\title{
Emissão de gases poluentes na construção civil: tema gerador para integração curricular
}

\author{
Emission of polluting gases in civil construction: generating theme for curriculum integration \\ Emisión de gases contaminantes en la construcción civil: tema generador para la integración
} curricular

Recebido: 22/11/2021 | Revisado: 29/11/2021 | Aceito: 02/12/2021 | Publicado: 13/12/2021

Tainá Souza Silva

ORCID: https://orcid.org/0000-0002-1453-7111 Instituto Federal da Paraíba, Brasil E-mail: taina.silva@ifpb.edu.br

Carlos Christiano Lima dos Santos ORCID: https://orcid.org/0000-0002-8428-1991 Universidade Estadual da Paraíba, Brasil E-mail: carloschristiano10@gmail.com

Poliana Sousa Epaminondas Lima ORCID: https://orcid.org/0000-0003-4700-1812 Instituto Federal da Paraíba, Brasil

E-mail: polis.epaminondas@yahoo.com.br

João Jarllys Nóbrega de Souza

ORCID: https://orcid.org/0000-0001-5546-3633 Universidade Federal da Paraíba, Brasil E-mail: jarllys@hotmail.com

\begin{abstract}
Resumo
No ensino técnico integrado ao médio, um dos grandes desafios dos docentes é a aproximação do mercado de trabalho com os conteúdos estudados em sala de aula. Questões relacionadas ao meio ambiente e sustentabilidade são exemplos de temas geradores, que podem e devem ser discutidos de forma interdisciplinar, nos currículos do ensino médio integrado. Diante disso, o objetivo desse artigo foi propor um estudo de caso com uma metodologia diferenciada, tendo como tema base a liberação de gases poluentes na construção civil. O trabalho foi desenvolvido junto a alunos da $2^{a}$ série do ensino técnico integrado em Edificações, de uma escola pública do Estado da Paraíba, sendo o método dividido em três etapas: aula expositiva na disciplina de Química II, visitas e análise de obras, e apresentação dos resultados para a turma. Os trabalhos apresentados pelos discentes evidenciaram a construção de importantes compreensões e interações entre conteúdos e conceitos da área básica e técnica.
\end{abstract}

Palavras-chave: Educação ambiental; Ensino integrado; Gases poluentes.

\begin{abstract}
In technical education integrated to high school, one of the greatest challenges for teachers is to bring the labor market closer to the contents studied in the classroom. Issues related to the environment and sustainability are examples of generative themes, which can and should be discussed in an interdisciplinary way, in the integrated secondary education curricula. Therefore, the objective of this article was to propose a case study with a different methodology, having as its base theme the release of polluting gases in civil construction. The work was developed with students from the 2nd grade of integrated technical education in Buildings, from a public school in the State of Paraíba, and the method was divided into three stages: lecture in Chemistry II, visits and analysis of works, and presentation of the results for the class. The works presented by the students evidenced the construction of important understandings and interactions between contents and concepts in the basic and technical areas.
\end{abstract}

Keywords: Environmental education; Integrated teaching; Polluting gases.

\section{Resumen}

En la educación técnica integrada a secundaria, uno de los mayores desafíos para los docentes es acercar el mercado laboral a los contenidos que se estudian en el aula. Los temas relacionados con el medio ambiente y la sostenibilidad son ejemplos de temas generativos, que pueden y deben ser discutidos de manera interdisciplinaria, en los planes de estudio integrados de la educación secundaria. Por tanto, el objetivo de este artículo fue proponer un caso de estudio con una metodología diferente, teniendo como tema base la liberación de gases contaminantes en la construcción civil. El trabajo se desarrolló con alumnos del 2do grado de educación técnica integrada en Edificios, de una escuela pública del Estado de Paraíba, y el método se dividió en tres etapas: charla de Química II, visitas y análisis de trabajos, y presentación de los resultados de la clase. Los trabajos presentados por los estudiantes evidenciaron la 
construcción de importantes entendimientos e interacciones entre contenidos y conceptos en las áreas básicas y técnicas.

Palabras clave: Educación ambiental; Enseñanza integrada; Gases contaminantes.

\section{Introdução}

O ensino médio integrado é uma modalidade de ensino em que ocorre a articulação entre a educação profissional técnica e o ensino propedêutico, conforme indicado pelo Decreto 5154/2004. Os cursos dessa modalidade de oferta têm por finalidade "proporcionar ao estudante conhecimentos, saberes e competências profissionais necessários ao exercício profissional e da cidadania, com base nos fundamentos científico-tecnológicos, sócio históricos e culturais" (Brasil, 2012). Para isso, é necessário desenvolver uma proposta curricular de formação integral, contemplando as dimensões do trabalho, da ciência, da tecnologia e da cultura (Silva, 2019).

Segundo Frigotto et al. (2005), a ideia de currículo integrado pode ser entendida em três dimensões que se complementam: a forma de oferta, o projeto de sociedade que almejamos construir, e a organização de um currículo interdisciplinar. Esse currículo deve possibilitar que os estudantes apreendam o conhecimento na sua totalidade e na sua relação com o mundo real, o que pode ser, por exemplo, através da integração entre conteúdos e componentes curriculares.

Segundo Suertegaray (2004), a interdisciplinaridade se constitui como uma prática coletiva, que tem como objetivo a busca da compreensão/explicação de um problema formulado pelo conjunto dos investigadores. Dessa forma, o trabalho interdisciplinar, exige assim, um rompimento com os problemas específicos de cada campo, colocando na pauta da pesquisa questões de estruturação mais complexa.

Apesar das diversas possibilidades de relacionar conteúdos e disciplinas, a união de componentes da base nacional comum e da parte profissional de um plano de curso integrado, independente da área, sempre foi um grande desafio, pois, a parte técnica visa o mercado de trabalho e a geral, a vida acadêmica, além de envolver professores de áreas diferentes, com olhares distintos (Nascimento et al. 2020).

Questões relacionadas ao meio ambiente e sustentabilidade são exemplos de temas geradores, que podem e devem ser discutidos de forma interdisciplinar, nos currículos do ensino médio integrado, abordando discussões sobre problemas ambientes, muitas das quais têm resultado em medidas políticas, técnico-científicas, institucionais e econômicas voltadas à proteção, recuperação e melhoria socioambiental (Marques et al., 2013). Segundo Sousa e colaboradores (2020), é preocupante a baixa adoção das práticas educativas dentro e fora do ambiente escolar, demonstrando ser necessário uma política efetiva em nível municipal, tendo a escola como elo entre a educação ambiental e a comunidade em geral.

Um exemplo de projeto interdisciplinar foi o desenvolvido por Rua e Souza (2010), o qual utilizou a Baía de Guanabara como pano de fundo para discussão de questões ambientais, envolvendo as disciplinas Química e Estudos Regionais do curso Técnico em Administração de Empresa.

Segundo Ferreira et al. (2020), é esperado que os profissionais que concluem o curso técnico integrado em Edificações possuam habilidades para projetar, executar e administrar empreendimentos, observando o contexto social e econômico da região em que estão inseridos, tendo a sustentabilidade, a ética e o respeito ao ser humano como princípios para a realização do seu trabalho.

Buscando promover o desenvolvimento sustentável, discussões sobre educação ambiental são bastante importantes e devem ser inseridas de forma interdisciplinar junto aos discentes do curso técnico integrado de Edificações, sabendo que a construção civil é uma atividade responsável pelo consumo excessivo de diversos recursos naturais de fontes não-renováveis, e pela geração de uma grande quantidade de resíduos (Melo et al. 2018).

A degradação de áreas provocada pela construção civil ocorre desde a extração de matérias-primas necessárias à fabricação de materiais de construção, até a execução de serviços no canteiro de obras e a disposição final dos resíduos por ela 
gerados. Além disso, a transformação de materiais brutos em bens e o transporte dos mesmos exige uma quantidade adicional de recursos, gerando gases (dióxido de carbono, metano, entre outros) responsáveis pelo efeito estufa (Barreto, 2005; Roth \& Garcias, 2009; Melo et al., 2018; Sanquetta et al. 2013).

Diante disso, a busca por incorporar práticas sustentáveis nas edificações é uma forma de promover igualdade social, valorização dos aspectos culturais, maior eficiência econômica e menor impacto ambiental nas soluções adotadas nas fases de projeto, construção, utilização, reutilização e reciclagem da edificação (Kronka Mülfarth, 1999).

Para isso, as instituições de ensino responsáveis pela formação de profissionais da área de edificações, tem a função de trazer a educação ambiental, sendo esta, uma importante ferramenta na construção de uma consciência ambientalmente crítica dos seus discentes e posteriores profissionais.

Mediante a constatação de que o ambiente pode se configurar como um meio propício para a contextualização de saberes e o tratamento interdisciplinar de determinados conceitos, o trabalho buscou por meio de uma proposta de ensino, verificar como a temática relacionada a liberação de gases poluentes a partir de materiais e processos da construção civil, pode contribuir com abordagens interdisciplinares, permitindo a integração entre conteúdos da área básica e técnica, e possibilitando a difusão da educação ambiental.

\section{Metodologia}

Inicialmente, foi trabalhado na disciplina de Química II, o conteúdo teórico de Gases, durante 4 aulas de 50 min, com duas turmas do segundo ano, do curso técnico integrado em Edificações, do Instituto Federal de Educação, Ciência e Tecnologia da Paraíba - Campus Catolé do Rocha. Ao final das aulas teóricas, foi discutido o texto "Pegada do carbono na construção civil: Estudo de caso que evitou a emissão de mais de 62000 ton de $\mathrm{CO}_{2}$ e reestruturou o setor de madeira nativa certificada no Rio de Janeiro", de Spignardi (2016), a fim de embasar e instigar os alunos a realizarem a próxima etapa, o trabalho prático.

Paralelo à disciplina Química II, os discentes também estavam cursando as disciplinas "Materiais de Construção" e "Construção Civil e Meio Ambiente". A disciplina "Materiais de Construção" tem como objetivo conhecer as propriedades dos diversos materiais empregados em construções civis, enquanto que a disciplina "Construção Civil e Meio Ambiente" tem como objetivo fornecer e atualizar conhecimentos básicos sobre gestão sustentável na construção de edifícios, envolvendo a discussão de conceitos e práticas de construção sustentável, aspectos legais ambientais, perdas e gestão de resíduos e tecnologias de sustentabilidade.

Para realização da etapa prática, a turma foi dividida em grupos de 4 alunos. Nessa etapa, os discentes deveriam escolher, na construção civil, alguma obra em andamento, acompanhá-la e realizar uma entrevista com os participantes da mesma, com a finalidade de analisar em quais etapas ocorriam a emissão de gases poluentes. A obra poderia estar acontecendo na cidade em que fica localizada a escola - Catolé do Rocha/ Paraíba - ou na cidade em que reside, uma vez que vários alunos moram em cidades vizinhas à Catolé do Rocha.

Após a coleta de dados in loco, o grupo deveria propor melhorias/estratégias para diminuição dessa emissão. Ou seja, a partir de uma situação problemática real, os alunos buscaram o conhecimento necessário para entendê-la, através de pesquisa bibliográfica, discussões em grupo ou diálogo com professores de sua e de outras disciplinas, além de técnicos envolvidos no assunto.

Todos os trabalhos foram entregues de forma escrita e apresentados em sala de aula, de forma oral, onde os alunos descreveram os resultados da entrevista e da análise da obra, além das propostas para diminuição de emissão de gases em cada uma delas. 


\section{Resultados e Discussão}

Para o desenvolvimento da atividade de campo, os discentes escolheram obras que estavam acontecendo em dez cidades do sertão da Paraíba, como Catolé do Rocha (local em que fica a escola) e cidades circunvizinhas (Figura 1).

Figura 1. Localização de Catolé do Rocha na Paraíba, e das cidades circunvizinhas, que foram escolhidas para análise das obras.

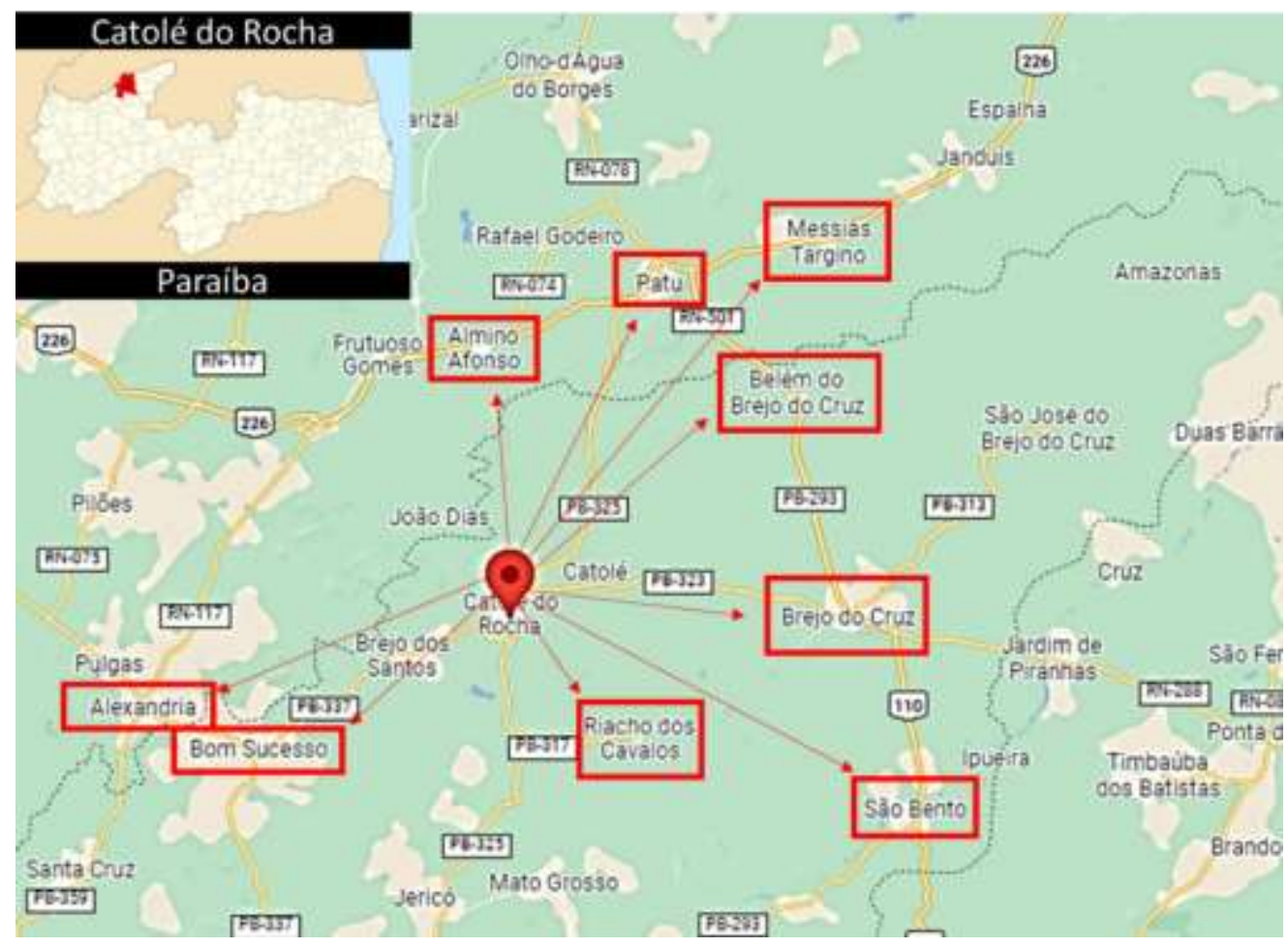

Fonte: Autores.

Na figura acima é possível observar que Catolé do Rocha fica situada no sertão da Paraíba. A microrregião polarizada por Catolé do Rocha é constituída dos seguintes municípios: Belém do Brejo do Cruz, Bom Sucesso, Brejo do Cruz, São José do Brejo do Cruz, Brejo dos Santos, Catolé do Rocha, Jericó, Riacho dos Cavalos, Mato Grosso e São Bento. Além desses municípios, Catolé do Rocha também fica próxima a cidades do Rio Grande do Norte, como Patu, Almino Afonso e Messias Targino (IBGE, 2020). Dessa forma, esse campus do Instituto Federal da Paraíba recebe estudantes de diversos municípios do entorno regional, tanto da Paraíba, quanto do Rio Grande do Norte.

A maior parte dos grupos escolheu analisar obras de construção ou reforma de residências particulares, entretanto, alguns decidiram analisar obras públicas, como pavimentação de ruas, reforma de escola e de Igreja (Gráfico 1, Figura 2). Dentre os grupos que analisaram a construção de uma residência, um deles escolheu a residência de um dos integrantes do grupo, havendo um maior acompanhamento e detalhamento da obra. 
Gráfico 1. Tipos de obras escolhidas para análise.

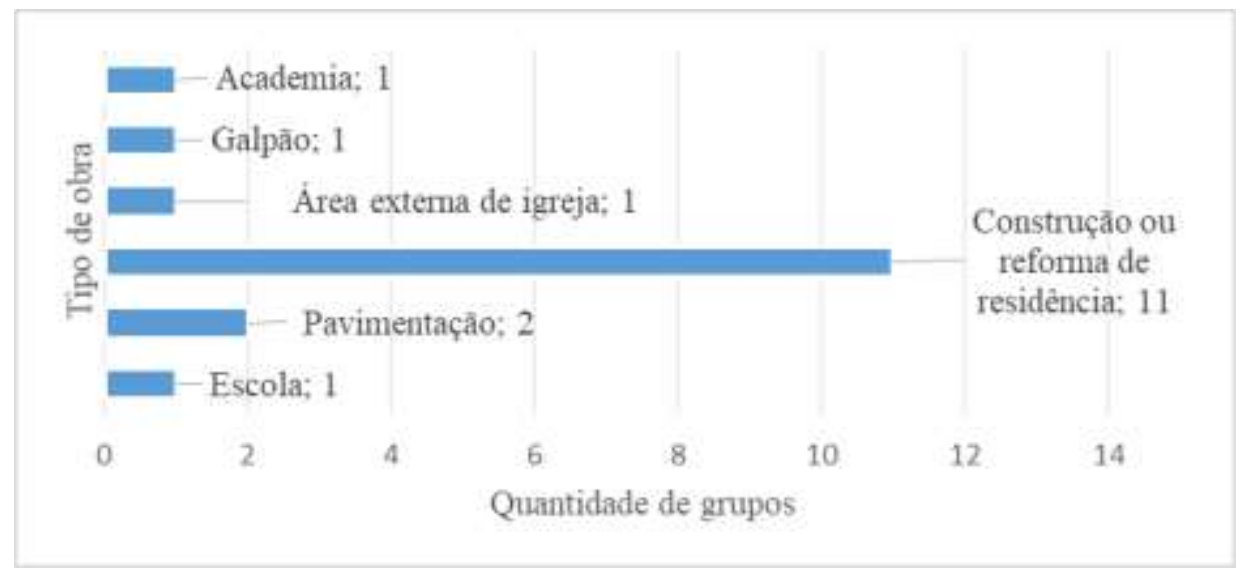

Fonte: Autores.

No Gráfico 1 é possível observar que 11 grupos optaram por analisar obras de construção ou reforma de residências, uma vez que esse tipo de obra é mais comum de se encontrar, além de ser mais acessível, entretanto, alguns grupos escolheram analisar obras de prédios comerciais, como academia e galpão, e outros elegeram obras públicas, como pavimentação de rua, construção de igreja e escola.

Figura 2. Exemplos de obras escolhidas e analisadas pelos alunos.
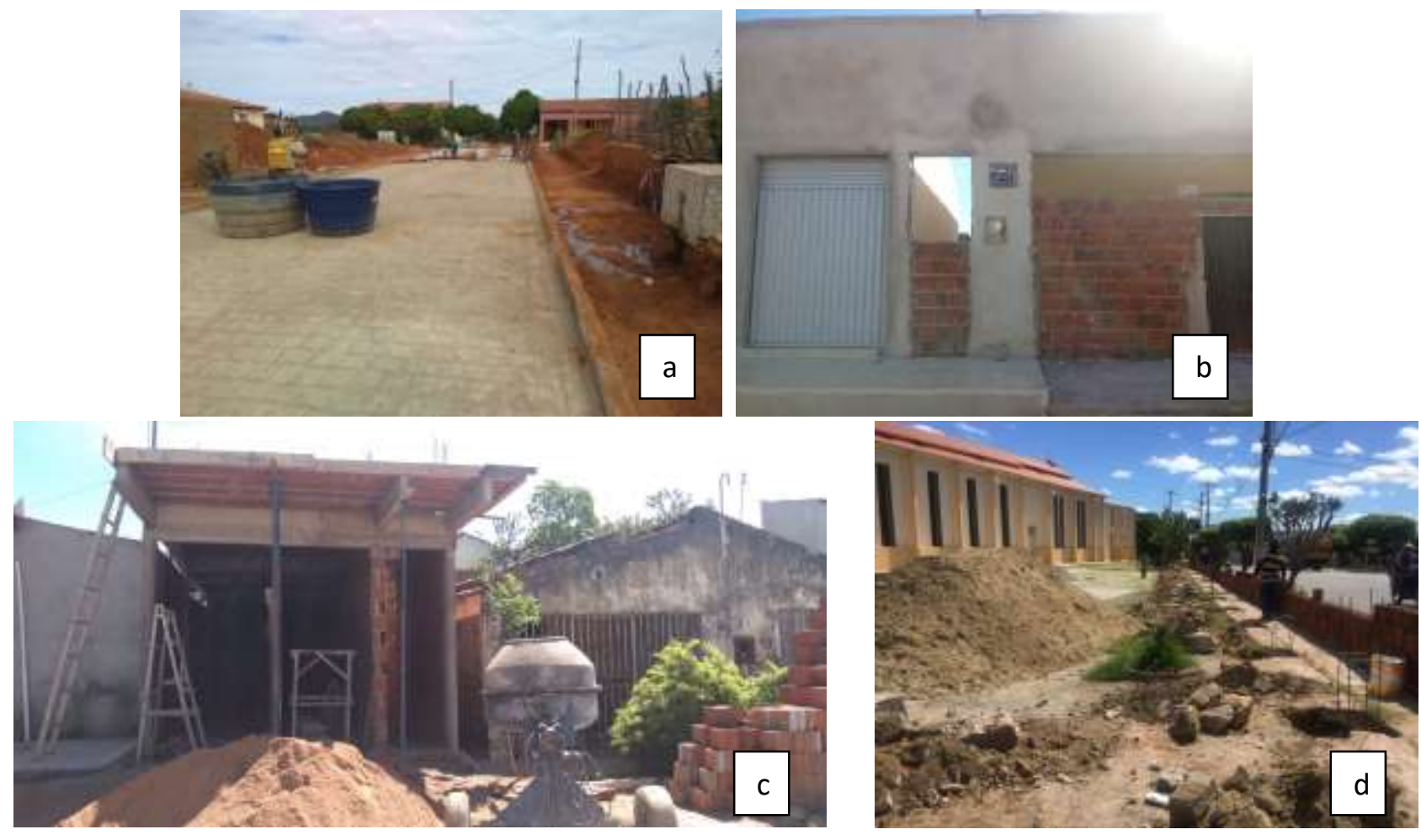

Fonte: Autores.

A Figura 2 apresenta exemplos das obras que foram escolhidas pelos estudantes, como uma pavimentação de uma rua em Brejo dos Santos - PB (2a), a construção de uma residência em Catolé do Rocha - PB (2b) e de uma academia em Bom Sucesso - PB (2c), e a reforma da área externa de uma Igreja em Brejo do Cruz-PB (2d). 
Cada grupo, após escolher a obra, elaborou um questionário de acordo com os dados observados no texto discutido inicialmente e com as pesquisas bibliográficas realizadas, buscando identificar os materiais e métodos utilizados, os locais de compra dos materiais e os resíduos gerados.

Ao visitar as obras, os discentes tiveram contato com mestres de obra, arquitetos, engenheiros e pedreiros, onde puderam aplicar o questionário, observar na prática as teorias estudadas sobre materiais de construção, tanto na disciplina básica quanto nas técnicas, além de analisar a obra como um todo.

Ao lidar com problemas reais, os alunos exercitam seu espírito reflexivo e crítico, importante para o exercício de sua profissão, quando terão de identificar eventuais problemas e resolvê-los. Esse contato com a realidade profissional estimula os alunos a pesquisar e buscar saídas para as questões apresentadas, além de proporcionar um elo entre os assuntos teóricos e a futura prática profissional do aluno (Guimarães \& Dorn, 2014; Nascimento et al., 2020).

Os materiais que os discentes identificaram foram: cimento, areia, brita, telha de cerâmica vermelha, tijolo, barras de ferro, cerâmica, tinta, canos de PVC, argamassa, pedras de paralelepípedo, entre outros.

Como proposta de melhoria para esse fator, os discentes trouxeram o incentivo a substituição dos materiais convencionais por materiais sustentáveis, como tinta ecológica, cimento verde e tijolo ecológico.

A partir desses dados, os discentes associaram os conteúdos das disciplinas Química, Materiais de Construção Civil e Construção Civil e Meio Ambiente, e realizaram pesquisas bibliográficas, identificando que ainda são utilizados materiais convencionais nas obras e que estes contribuem bastante com a emissão de gases na atmosfera, desde a sua extração até a fabricação e transporte do produto final.

Pensar a interdisciplinaridade enquanto processo de integração recíproca entre as várias áreas de conhecimento é sem dúvida, uma tarefa que demanda um grande esforço no rompimento de uma série de obstáculos, devendo ser desenvolvida uma visão integrada do meio em que vivemos. A integração de conceitos e saberes, nesse caso, foi potencializada, no momento em que alunos teceram relações mais intrínsecas entre as diversas áreas, gerando maiores sentidos e significados para os conhecimentos discutidos em sala de aula (Costa et al., 2021; Júnior et al., 2019).

Ao questionarem sobre o local de compra dos materiais, os discentes identificaram que em 52\% das obras analisadas, o material foi adquirido em outras cidades, havendo deslocamento até a obra através de caminhões e/ou carros próprios. Tal fato, segundo Carvalho (2014), associado ao crescimento do número de veículos automotores movidos à combustíveis fósseis, ao descumprimento de processos regulatórios de manutenção, inspeção e fiscalização e a não renovação da frota têm sido fatores do aumento da concentração de gases poluentes na atmosfera.

Com relação a esse fator, os discentes propuseram as seguintes melhorias para diminuição da emissão de gases poluentes: manutenção de veículos, comprar materiais em locais mais próximos, interação entre construtoras para compras coletivas e uso de biocombustíveis.

A geração de resíduos sólidos e liberação de gases tóxicos foi observada por alguns grupos, havendo relato de queima de resíduos das obras e acúmulo de materiais em locais próximos à obra e em "lixões" da cidade. A partir desse resultado, os discentes foram instigados a buscar resoluções que estabeleçam diretrizes para regulação e fiscalização da gestão de resíduos da construção civil, sugerindo o reuso de materiais, reflorestamento e maior fiscalização.

De acordo com Spignardi (2016), que realizou um estudo de caso no Rio de Janeiro, a coleta seletiva e o reaproveitamento dos resíduos desviaram do aterro mais de $80 \%$ dos resíduos gerados na obra, além de reduzirem o transporte e as emissões dos resíduos destinados a aterro ou incineração.

Uma parte fundamental das ações de regulação e fiscalização da gestão de resíduos da construção civil encontra-se nas mãos do poder público municipal. A Resolução CONAMA n 307, de 05 de julho de 2002, estabelece diretrizes, critérios e procedimentos para uma correta gestão. Dentre estes, no que diz respeito às responsabilidades, estabelece que os grandes 
geradores, como empresas privadas de construção, deverão elaborar projetos próprios especificando o gerenciamento dos resíduos, cabendo aos municípios a elaboração de procedimentos para o exercício das responsabilidades dos pequenos geradores, na forma de um Programa Integrado de Gerenciamento dos Resíduos da Construção Civil (Santos, 2019).

Segundo Soares et al. (2021), para que o conhecimento se efetive de fato, o mesmo requer uma relação constante entre teoria e prática proporcionando, através de várias metodologias, a absorção contínua de conhecimento. Durante a apresentação dos trabalhos, os discentes puderam expor suas vivências de campo, além dos resultados de suas pesquisas, demonstrando a integração entre os conhecimentos técnicos e básicos, construída a partir da investigação e de discussões realizadas entre eles, os profissionais entrevistados e os professores. Dessa forma, os estudantes se tornaram parte do processo de ensino e aprendizagem, pois, além de serem os principais interessados em aprender algo, conseguiram perceber qual dinâmica educacional the permitiu construir o conhecimento de forma mais efetiva e, consequentemente, armazenar esse entendimento em sua memória (Ferreira Júnior et al., 2020).

Segundo Martins, Lima e Freire, é importante frisar que a associação da formação geral com a formação profissional no ensino médio, não é por si só suficiente para que ocorra integração curricular. Desta forma, a interdisciplinaridade pode se apresentar como um elemento integrador, levando a uma nova atitude para reconexão dos saberes, expansão do conhecimento e uma aprendizagem com mais sentido para vida das pessoas.

\section{Conclusão}

A construção civil tem um papel fundamental no desenvolvimento social e urbano, mas, gera impactos na natureza. Dessa forma, a educação ambiental atua como agente responsável pela modificação desse cenário, sendo capaz de trazer uma mudança positiva na maneira como os profissionais da área de construção civil exercem suas funções.

A temática abordada neste trabalho contribuiu para formação de indivíduos que possuam uma consciência ambiental crítica, sendo esses capazes de elaborar respostas para as mais diversas questões ambientais da atualidade.

Portanto, por se tratar de uma temática ampla e complexa, espera-se que os resultados desta pesquisa possam servir de modelo e motivação para que novas metodologias possam ser desenvolvidas para construção e produção de conhecimento de forma integrada e interdisciplinar, em cursos técnicos integrados ao médio, uma vez que dificilmente encontraremos algum campo de saber que não tenha relação com nenhum outro.

\section{Referências}

Barreto, I. M. C. M. B. D. N. (2005). Gestão de resíduos na construção civil. Sinduscon.

Brasil. Diretrizes Curriculares para a Educação Profissional. Ministério da Educação. Secretaria de Educação Básica. Brasília, 2012.

Carvalho, L. A. H. (2014). Impactos ambientais: emissão de gases poluentes por veículos automotores na Av. Luís Vianna Filho (Dissertação de Mestrado). Universidade Salvador - UNIFACS, Salvador, Brasil.

Costa, J. I. P., Gomes, A. M. S., Ferreira, J. S. S., Barroso, J. C., Santiago, P. A. L., \& Santiago, S. R. S. S. (2021). A Educação Ambiental como Proposta Interdisciplinar para Estudantes do Ensino Médio em uma Escola da Rede Pública Estadual de Manaus-AM. Research, Society and Development, 10(13).

Ferreira, T. R., Canaval, J. H., \& Junior, E. C. (2020). Investigação dos perfis de aprendizado na Engenharia Civil e no Técnico em Edificações sob a ótica dos alunos do Instituto Federal de Minas Gerais (IFMG). Research, Society and Development, 9(11).

Franco, M. A. (2005). Pedagogia da pesquisa-ação. Educação e Pesquisa. 31(3), 483-502.

Frigotto, G., Ramos, M., \& Ciavatta, M. (2005). Ensino Médio Integrado: concepção e contradições. Ed. Cortez, 106-127.

Guimarães, C. C., \& Dorn, R. C. (2014). Ensino Técnico Baseado em Problemas: Um relato de caso no SENAIS de Feira de Santana. Contexto \& Educação, 29 (92).

IBGE, Divisão Territorial Brasileira - DTB 2020. Disponível em: https://cidades.ibge.gov.br/brasil/pb/catole-do-rocha/panorama. Acessado em dezembro 2021. 
Júnior, S. L., Almeida, D. A., Menezes, L. C. C., \& Greco, R. (2019). O ambiente natural como recurso para promover um ensino interdisciplinar. Química Nova na Escola, 41(4), 369-376.

Kronka Mülfarth, R. C. (2003). Arquitetura de baixo impacto humano e ambiental. (Tese de Doutorado). FAU-USP

Marques, C. A., Silva, R. M. G., Gonçalves, F. P., Fernandes, C. S., Sangiogo, F. A., \& Regiani, A. M. A (2013). Abordagem De Questões Ambientais: Contribuições De Formadores De Professores De Componentes Curriculares Da Área De Ensino De Química. Química Nova, $36(4), 600-606$.

Martins, W. C., Lima, P. F. R., \& Freire, L. B. O. (2020) A Interdisciplinaridade no Ensino Médio Integrado à Educação Profissional. Research, Society and Development, $9(1)$.

Melo, R. R. M., Oliveira, D. K. S., Andrade, J. H. P., Soares, V. J. M., \& Santos, A. A. (2018). Educação Ambiental: Ferramenta Fundamental Para A Formação Dos Técnicos Em Edificações Do IFPB - Campus Patos. In Anais do V Congresso Nacional de Educação, Olinda, PE. https://editorarealize.com.br/artigo/visualizar/47049.

Nascimento, T. L., Bertini, L. M., \& Rios, M. A. S. (2020). A realização de visitas técnicas na formação profissional do Técnico em Química: um estudo de caso. Research, Society and Development, $9(8)$.

Roth, C. G., Arcias, C. M. (2009). Construção civil e a degradação ambiental. Desenvolvimento em Questão, 7(13), 111-128. http://www.redalyc.org/articulo.oa?id=75212355006.

Rua, E. R., Souza, P. S. A. (2010). Educação ambiental em uma abordagem Interdisciplinar e contextualizada por meio das disciplinas Química e Estudos Regionais. Química Nova na Escola, 32(2), 95-100.

Sanquetta, C. R., Flizikowski, L. C., Corte, A. P. D., Mognon, F., \& Maas, G. C. B. (2013). Estimativa das emissões de gases de efeito estufa em uma obra de construção civil com a metodologia Ghg Protocol. Enciclopédia Biosfera, Centro Científico Conhecer - Goiânia, 9(16), 1088.

Santos, A. S., Iselle, F. A., \& Dias-Silva, L. H. (2019). Resíduos da construção civil: conceitos, histórico e gerenciamento. Revista Eletrônica Organizações e Sociedade. 8(10), 5-21.

Silva, H. H. (2019). Integração curricular: uma proposta interdisciplinar baseada em sequências didáticas no Curso Técnico em Edificações. (Dissertação de mestrado). Instituto Federal do Espírito Santo, Programa de Pós-graduação em Educação Profissional e Tecnológica, Vitória.

Soares, M. S., Mauriz, T. R. M., Ayres, M. C. C., Silva, J. S., Costa, C. R. M., Lima, J. F., Lavor, C., Lima, G. F., Vieira, D. F., \& Moura, L. F. W. (2021). O uso de metodologias ativas de ensino por professores de Ciências nas escolas de Angical -PI. Research, Society and Development, 10(13).

Sousa, S. N. F., Rebello, F. K., Cordeiro, L. P., Cardoso, C. M., \& Santos, M. A. S. (2020). Educação ambiental na Amazônia: contexto e prática de professores no município de Colares, no Estado do Pará, Brasil. Research, Society and Development, 9(7), 1-31.

Spignardi, M. C. M. (2016). Pegada de carbono na construção civil: Estudo de caso que evitou a emissão de mais de 62.000 ton $\mathrm{CO}_{2}$ e reestruturou o setor de madeira nativa certificada no Rio de Janeiro. In Anais do Encontro Internacional sobre Gestão Empresarial e Meio Ambiente, São Paulo, SP. Disponível em: http://engemausp.submissao.com.br/18/anais/resumo.php?cod_trabalho=19. Acessado em Setembro 2021.

Suertegaray, D. M. A. Ambiência e pensamento complexo: Resignific(ação) da Geografia. In: Silva, A.D. \& Galeno, A. (orgs.). (2004). Geografia - Ciência do Complexus. Ensaios Transdisciplinares. Sulina/UFPR. 